\title{
Metabolic flux profiling of recombinant protein secreting Pichia pastoris growing on glucose: methanol mixtures
}

\author{
Joel Jordà', Paula Jouhten², Elena Cámara' , Hannu Maaheimo², Joan Albiol ${ }^{1}$ and Pau Ferrer ${ }^{*}$
}

\begin{abstract}
Background: The methylotrophic yeast Pichia pastoris has emerged as one of the most promising yeast hosts for the production of heterologous proteins. Mixed feeds of methanol and a multicarbon source instead of methanol as sole carbon source have been shown to improve product productivities and alleviate metabolic burden derived from protein production. Nevertheless, systematic quantitative studies on the relationships between the central metabolism and recombinant protein production in P. pastoris are still rather limited, particularly when growing this yeast on mixed carbon sources, thus hampering future metabolic network engineering strategies for improved protein production.

Results: The metabolic flux distribution in the central metabolism of $P$. pastoris growing on a mixed feed of glucose and methanol was analyzed by Metabolic Flux Analysis (MFA) using ${ }^{13} \mathrm{C}-\mathrm{NMR}$-derived constraints. For this purpose, we defined new flux ratios for methanol assimilation pathways in $P$. pastoris cells growing on glucose:methanol mixtures. By using this experimental approach, the metabolic burden caused by the overexpression and secretion of a Rhizopus oryzae lipase (Rol) in P. pastoris was further analyzed. This protein has been previously shown to trigger the unfolded protein response in P. pastoris. A series of ${ }^{13} \mathrm{C}$-tracer experiments were performed on aerobic chemostat cultivations with a control and two different Rol producing strains growing at a dilution rate of $0.09 \mathrm{~h}^{-1}$ using a glucose:methanol 80:20 (w/W) mix as carbon source.

The MFA performed in this study reveals a significant redistristribution of carbon fluxes in the central carbon metabolism when comparing the two recombinant strains vs the control strain, reflected in increased glycolytic, TCA cycle and NADH regeneration fluxes, as well as higher methanol dissimilation rates.

Conclusions: Overall, a further ${ }^{13} \mathrm{C}$-based MFA development to characterise the central metabolism of methylotrophic yeasts when growing on mixed methanol:multicarbon sources has been implemented, thus providing a new tool for the investigation of the relationships between central metabolism and protein production. Specifically, the study points at a limited but significant impact of the conformational stress associated to secretion of recombinant proteins on the central metabolism, occurring even at modest production levels.
\end{abstract}

\section{Background}

Pichia pastoris is an attractive system for the production of recombinant proteins [1-4]. Moreover, the development of systems biotechnology tools specific for this cell factory [5-10] has opened new opportunities for strain improvement and rational design of culture conditions.

Several studies have reported on the impact of recombinant protein over expression on different growth parameters of yeast, such as maximum growth rate, biomass

\footnotetext{
* Correspondence: pau.ferrer@uab.cat

'Departament d'Enginyeria Química, Escola d'Enginyeria|, Universitat

Autònoma de Barcelona, Bellaterra (Cerdanyola del Vallès), Spain

Full list of author information is available at the end of the article
}

yield or substrate specific consumption rate [11-14], suggesting a potential impact on the cell's central metabolism. Nevertheless, the number of quantitative studies investigating the potential interactions between $P$. pastoris' central carbon metabolism, environmental conditions and recombinant protein production still remains very limited [9,15-18].

The AOX1 promoter of P. pastoris has been widely used for recombinant protein production. The conceptual basis for this expression system stems from the observation that some of the enzymes required for methanol metabolism are present at substantial levels only when cells are grown on this substrate [19]. Furthermore, catabolite repression

\section{Biomed Central}


by different multicarbon compounds is particularly tight in $P$. pastoris. Interestingly, mixed carbon strategies (mixing methanol with a multicarbon source such as sorbitol or glycerol) have proven to boost productivity levels significantly $[2,20]$, also suggesting that metabolic burden caused by recombinant protein production can be reduced [21].

Overproduction of recombinant proteins may lead to their partial accumulation as misfolded or folding-reluctant protein species within organelles of the secretory pathway, causing considerable stress in the host [22]. This is the case of a Rhizopus oryzae lipase (Rol), which has been used as a model protein for several physiological studies of recombinant $P$. pastoris. In particular, over expression of this protein has been shown to trigger the unfolded protein response (UPR) [23], partially explaining its negative effect on cell growth [12]. Even though the unfolded protein response is well characterised in yeast, there are very limited quantitative studies on the potential interactions between an endogenous stress factor (recombinant protein secretion), environmental conditions and the core metabolism.

In this study, biosynthetically directed fractional (BDF) ${ }^{13} \mathrm{C}$-labeling was employed to elucidate the effect of protein burden on the central carbon metabolism of $P$. pastoris. Specifically, this study focuses on comparison between three different strains of $P$. pastoris, two strains producing different amounts of Rol under the control of the $A O X 1$ promoter (due to different $R O L$ gene dosage) and the corresponding control strain. In this way, we aimed at analyzing quantitatively the potential impact (metabolic burden) of recombinant protein secretion on the core and energy metabolism of $P$. pastoris.

\section{Results and discussion}

Growth and product formation of recombinant $P$. pastoris strains

There are only few physiological studies on the potential impact of recombinant protein production on the core metabolism of $P$. pastoris, particularly for those cases where the product is secreted $[9,15]$. The aim of our study was to quantify the potential metabolic burden caused by recombinant $R$. oryzae lipase (Rol) secretion on this yeast. This enzyme has proven to be an attractive model for physiological studies of protein production in $P$. pastoris; its over expression triggers the unfolded protein response [23] and it has a negative impact on cell growth parameters, particularly in strains expressing multiple copies of the ROL gene [12]. Most notably, Rol secretion levels obtained in $P$. pastoris high cell density cultures are rather moderate (around 300 500 $\mathrm{mg} \mathrm{L}^{-1}$ ) [24]. To characterise the potential intracellular carbon flux redistribution due to recombinant Rol secretion, we performed chemostat aerobic cultivations using a fixed mixture of glucose:methanol $(80 \%: 20 \%, w / w)$ at a dilution rate of $0.09 \mathrm{~h}^{-1}$ for two $P$. pastoris strains producing different amounts of Rol, as well as for the corresponding control strain. The selected dilution rate is below the maximum specific growth rate $\left(\mu_{\max }\right)$ of the original Rolproducing strain growing on glucose $\left(0.18 \mathrm{~h}^{-1}\right)$ [5], and slightly above the $\mu_{\max }$ of this strain growing on methanol $\left(0.07 \mathrm{~h}^{-1}\right)$ [6], as unique carbon sources. Under these conditions, continuous cultures were carbon-limited, thereby allowing partial glucose derepression of the methanol assimilation pathway, as well as its induction by methanol [25]. Notably, no metabolic by-products could be detected in the culture broth in any of the cultivations. As expected from previous studies, the physiology of $P$. pastoris was affected by Rol overproduction (Table 1). In particular, the specific glucose consumption rate increased significantly from 0.76 to about $0.9 \mathrm{mmol}$ $\mathrm{g}^{-1} \mathrm{~h}^{-1}$ when comparing the reference strain to the two Rol-producing strains, respectively, whereas specific methanol consumption rates were not significantly altered. Furthermore, Rol production also resulted in increased $\mathrm{CO}_{2}$ exchange rate (CER) and oxygen uptake rate (OUR) values. Conversely, the physiological differences between the two Rol-producing strains were insignificant, even though extracellular lipase activity levels for the ROL 2-copy strain were about 1.4-fold higher than in the ROL 1-copy strain. Overall, such impact on growth performance is remarkable, since total extracellular protein levels were relatively low (ca. $30 \mathrm{mg} \mathrm{L}^{-1}$ ) in both Rol-producing strains and, furthermore, Rol represented only a fraction (ca. 35-40\%) of the total extracellular protein. Therefore, it seemed unlikely that its impact on the physiology of the host could be largely

Table 1 Growth parameters of $P$. pastoris growing on glucose:methanol in chemostats cultures

\begin{tabular}{|c|c|c|c|c|c|c|c|c|}
\hline Strain & $\begin{array}{l}\text { Glucose } \\
\mathrm{mmol} / \mathrm{g} \\
\mathrm{CDW} \cdot \mathrm{h}\end{array}$ & $\begin{array}{l}\text { Methanol } \\
\mathrm{mmol} / \mathrm{g} \\
\mathrm{CDW} \cdot \mathrm{h}\end{array}$ & $\begin{array}{l}\text { OUR } \mathrm{mmol} / \mathrm{g} \\
\text { CDW } \cdot \mathrm{h}\end{array}$ & $\begin{array}{l}\text { CER } \mathrm{mmol} / \mathrm{g} \\
\mathrm{CDW} \cdot \mathrm{h}\end{array}$ & $\begin{array}{l}\text { Biomass } \\
\mathrm{mmol} / \mathrm{g} \\
\mathrm{CDW} \cdot \mathrm{h}\end{array}$ & $\begin{array}{l}\mathrm{Y}_{\mathrm{X} / \mathrm{s}} \mathbf{g} \\
\mathrm{CDW} / \mathrm{Cmol}\end{array}$ & $\mathrm{RQ}$ & $\begin{array}{l}\text { Lipase activity } \\
\text { AU/gCDW }\end{array}$ \\
\hline X-33 control & $-0.76 \pm 0.02$ & $-1.15 \pm 0.06$ & $-2.95 \pm 0.11$ & $2.31 \pm 0.11$ & $3.40 \pm 0.04$ & $14.7 \pm 0.3$ & $0.78 \pm 0.05$ & n.d. \\
\hline ROL 1-copy & $-0.85 \pm 0.01$ & $-1.29 \pm 0.05$ & $-3.71 \pm 0.07$ & $3.04 \pm 0.06$ & $3.32 \pm 0.03$ & $13.0 \pm 0.3$ & $0.82 \pm 0.09$ & $2504 \pm 192$ \\
\hline ROL 2-copy & $-0.87 \pm 0.01$ & $-1.24 \pm 0.09$ & $-3.66 \pm 0.06$ & $3.04 \pm 0.04$ & $3.39 \pm 0.05$ & $12.9 \pm 0.1$ & $0.83 \pm 0.07$ & $3490 \pm 208$ \\
\hline
\end{tabular}

Reconciled measured substrates and products consumption or production rates at steady state conditions in each experiment. Substrate consumption, biomass and metabolites production rates for each strain. OUR, Oxygen Uptake Rate; $\mathrm{CER}, \mathrm{CO}_{2}$ Exchange Rate; RQ Respiratory Quotient; n.d., not detectable. Consistency index $\mathrm{h}$ was below 7.81 for a redundancy of 3 (95\% significance level) in all cases. 
Table 2 Biomass C-molecular composition for $\boldsymbol{P}$. pastoris

\begin{tabular}{|c|c|c|c|c|c|}
\hline \multicolumn{6}{|l|}{$A$} \\
\hline Strain & Carbon source & C-mol Biomass formula & C:N Ratio & H:O Ratio & $\gamma$ \\
\hline X-33 control & $80 \%$ Glucose 20\% Methanol & $\mathrm{CH}_{1.687} \mathrm{~N}_{0.17} \mathrm{O}_{0.635} \mathrm{~S}_{0.002}$ & 5.9 & 2.7 & 3.9 \\
\hline ROL 1-copy & 80\% Glucose 20\% Methanol & $\mathrm{CH}_{1.749} \mathrm{~N}_{0.141} \mathrm{O}_{0.679} \mathrm{~S}_{0.002}$ & 7.1 & 2.6 & 4.0 \\
\hline ROL 2-copy & 80\% Glucose 20\% Methanol & $\mathrm{CH}_{1.702} \mathrm{~N}_{0.14} \mathrm{O}_{0.643} \mathrm{~S}_{0.002}$ & 7.1 & 2,6 & 4.0 \\
\hline X-33 control* & $100 \%$ Glucose & $\mathrm{CH}_{1.761} \mathrm{~N}_{0.143} \mathrm{O}_{0.636} \mathrm{~S}_{0.0018}$ & 7.0 & 2.8 & 4.1 \\
\hline S. cerevisiae ${ }^{* *}$ & 100\% Glucose & $\mathrm{CH}_{1.748} \mathrm{~N}_{0.148} \mathrm{O}_{0.596} \mathrm{~S}_{0.0018}$ & 6.8 & 2.9 & 4.2 \\
\hline
\end{tabular}

*Data taken from [26] ; ** Data taken from [27].

Biomass C-molecular formula for $P$. pastoris growing on glucose:methanol mixture (80:20) as a carbon source in chemostat cultures at a $D=0.09 \mathrm{~h}^{-1}$, expressed as $\mathrm{C}$-molecular formula. $\mathrm{C}: \mathrm{N}$, carbon:nitrogen ratio; $\mathrm{H}: \mathrm{O}$, hydrogen:oxygen ratio. $\gamma$, reduction degree of the biomass.

attributed to an increased demand for Rol precursors, but rather as a result of the stress caused to the cell.

Growth conditions and genetic background can have a significant impact on both the elementary and macromolecular composition of cells. Consequently, detailed knowledge of their composition is important for metabolic flux analysis purposes. As there was no such data available for $P$. pastoris growing in glucose:methanol mixtures, determination of elementary composition, protein and carbohydrates (that is, the major cell components, constituting up to $90 \%$ of the cell's dry weight) content, as well as amino acid composition analyses were performed for all of the strains, as shown in Tables 2, 3 and 4 (see also Additional file 1). These analyses revealed that there are significant differences $(p$-value $<0.05)$ in terms of relative protein content among cultures grown on different carbon sources (glucose vs. glucose:methanol), as well as among Rol-producing and control (nonproducing) strains. Moreover, several amino acids relative amounts differed significantly $(p$-value $<0.05)$ when comparing the control strain to the Rol 1-copy strain (Thr and Ala) and to the Rol 2-copy strain (Thr, Ala, Glu, Cys, Met, Orn and Arg) (Table 4). Coherent with the total protein content analyses, the amount of most amino acids was generally higher in cells growing on glucose:methanol than when growing on glucose as a sole carbon source. Following this observation, it was considered that both the carbon source(s) and strain type would have an impact on the calculated metabolic fluxes and, therefore, it was decided to consider a different biomass composition for each of the three strains growing on glucose:methanol (Table 2 and 3).

Impact of methanol co-assimilation on the central carbon metabolism of $P$. Pastoris growing on glucose methanol mixtures

The $2 \mathrm{D}{ }^{1} \mathrm{H}-{ }^{13} \mathrm{C}-\mathrm{HSQC}$ spectra were analysed as described by [28] and [29], yielding the relative abundances of intact $\mathrm{C} 2$ and $\mathrm{C} 3$ fragments in proteinogenic amino acids $f$-values (Additional file 2). Analysis of the $f$-values were coherent with the biosynthetic pathways of proteinogenic amino acids in yeast, as already shown in previous studies of $P$. pastoris [5]. The use of the C6 source glucose and C1 source methanol for $\mathrm{BDF}{ }^{13} \mathrm{C}$-labelling of proteinogenic amino acids enabled the determination of the flux ratios for reactions associated with the assimilation of $\mathrm{C} 1$ source by the cell. When yeast are grown on glucose as a sole carbon source, the $f$-values of His-C $\alpha$ and Phe-C $\alpha$ must be equal or practically equal due to the effect of transaldolase and transketolase reactions [15,30]. However, these two patterns were different in our experiments (Additional file 2), providing a direct evidence of assimilation of methanol for cell growth and maintenance, as well as proving that glucose limiting conditions allow for induction of the methanol assimilation pathways by the latter substrate. Similar evidence has also previously been observed in P. pastoris cells, growing in glycerol:methanol mixtures, under carbon-limiting conditions [6].

When comparing glucose vs glucose:methanol carbon flux distributions in P. pastoris cells growing aerobically in

Table 3 Biomass macromolecular composition for $\boldsymbol{P}$. pastoris

\begin{tabular}{llllll}
\hline B & \multicolumn{1}{l}{} & & \\
\hline Strain & Protein $\mathbf{w} / \mathbf{w}$ & Carbohydrate $\mathbf{w} / \mathbf{w}$ & Lipids $^{*} \mathbf{w} / \mathbf{w}$ & RNA $^{*} \mathbf{w} / \mathbf{w}$ & DNA $^{*} \mathbf{w}^{\mathbf{w}}$ \\
\hline$X$-33 control & $0.49 \pm 0.02$ & $0.31 \pm 0.01$ & $0.02 \pm 0.02$ & $0.07 \pm 0.007$ & $0.001 \pm 0.0001$ \\
ROL 1-copy & $0.43 \pm 0.02$ & $0.34 \pm 0.01$ & $0.04 \pm 0.02$ & $0.06 \pm 0.007$ & $0.001 \pm 0.0001$ \\
ROL 2-copy & $0.43 \pm 0.03$ & $0.34 \pm 0.01$ & $0.05 \pm 0.02$ & $0.07 \pm 0.007$ & $0.001 \pm 0.0001$ \\
\hline
\end{tabular}

* calculated values.

Biomass macromolecular formula for $P$. pastoris growing on glucose:methanol mixture $(80: 20)$ as a carbon source in chemostat cultures at a $D=0.09 \mathrm{~h}^{-1}$. Data given as percentage of dry cell weight. 
Table 4 Amino acid composition of $\boldsymbol{P}$. pastoris

\begin{tabular}{|c|c|c|c|c|c|}
\hline \multirow[b]{2}{*}{$\% \mathrm{~mol} / \mathrm{mol}$} & \multicolumn{3}{|c|}{$80 \%$ Glucose $20 \%$ Methanol } & \multicolumn{2}{|c|}{$100 \%$ Glucose } \\
\hline & $\mathrm{X}-33$ & ROL 1-copy & ROL 2-copy & $\mathrm{X}-33^{*}$ & S. cerevisiae ${ }^{* *}$ \\
\hline Arg & 8.15 & 7.67 & 6.45 & 7.04 & 3.86 \\
\hline Asp & 9.25 & 9.48 & 10.05 & 8.78 & 9.28 \\
\hline Thr & 6.15 & 6.06 & 6.46 & 5.88 & 5.57 \\
\hline Ser & 6.34 & 6.32 & 6.82 & 6.26 & 5.33 \\
\hline Glu & 15.76 & 15.44 & 13.23 & 17.81 & 15.48 \\
\hline Pro & 4.2 & 4.0 & 3.92 & 3.83 & 4.22 \\
\hline Gly & 7.80 & 7.53 & 7.86 & 6.86 & 8.89 \\
\hline Ala & 11.14 & 9.41 & 9.36 & 10.40 & 9.77 \\
\hline Val & 6.81 & 6.67 & 6.54 & 5.88 & 7.33 \\
\hline Cys & 0.17 & 0.19 & 0.13 & 0.15 & 0.14 \\
\hline Met & 0.78 & 0.75 & 0.62 & 0.79 & 1.14 \\
\hline Ile & 4.49 & 4.49 & 4.69 & 4.64 & 5.89 \\
\hline Leu & 7.50 & 7.45 & 8.34 & 6.96 & 8.01 \\
\hline Tyr & 2.28 & 2.19 & 2.51 & 2.16 & 1.96 \\
\hline Phe & 3.44 & 3.31 & 3.61 & 3.20 & 3.76 \\
\hline Orn & 0.68 & 0.32 & 0.26 & 1.04 & 0.24 \\
\hline Lys & 6.77 & 6.77 & 7.21 & 6.41 & 6.57 \\
\hline His & 2.10 & 1.94 & 1.95 & 1.89 & 1.93 \\
\hline Trp & 1.00 & 1.00 & 1.00 & 1.40 & 1.96 \\
\hline
\end{tabular}

* Data taken from [26]; ** Data taken from [27].

Amino acid composition of the whole cell extract for all the $P$. pastoris strains tested. Amino acid composition measured for the three different $R O L$ gene dosages. Data given as percentage of each amino acid in the total pool of amino acids. The standard deviation of the analytical method was 3 5\%.

carbon-limited chemostat cultures, a clear impact of methanol assimilation is observed on the metabolic network operation (Figure 1). The split ratio between the glycolytic and the oxidative branch of the pentose phosphate pathway (PPP) fluxes was clearly shifted to the latter pathway in glucose:methanol grown cells, probably reflecting the demand of pentose phosphates for methanol assimilation. Also, cells growing in the mixed substrate presented a significantly lower flux through the tricarboxylic acids (TCA) cycle (normalized to the glucose uptake rate). This difference was also reflected in the calculated $\mathrm{NADH}$ regeneration rates (Figure 1). Interestingly, Solà and the co-workers [6] did not detect significant differences in the relative TCA cycle activity when comparing cells grown on glycerol vs glycerol:methanol mixtures. As expected from early mixed substrate studies of methylotrophic yeasts [31], methanol co-assimilation resulted in slightly lower biomass yield $(14.3 \pm 0.3 \mathrm{~g}$ CDW/ C-mol) compared with glucose-only grown cultures $(16.8 \pm 1.2 \mathrm{~g}$ CDW/ C-mol). Nevertheless, considering the standard deviations of these calculated values, further experimental data would be required to confirm this tendency. Most notably, most methanol (about $80 \%$ ) was directly dissimilated to $\mathrm{CO}_{2}$, as opposite to cells growing on methanol as sole carbon source under limiting conditions [16]. Methanol co-assimilation has an important effect on the bioenergetics of methylotrophic yeasts. For instance, direct oxidation of methanol to $\mathrm{CO}_{2}$ via formaldehyde and formate (see Figure 1) yields two $2 \mathrm{NADH}$ mols per methanol mol. Early studies on methanol metabolism showed that the enzymes for primary oxidation and assimilation of methanol or formaldehyde are under inhibitory control of energy equivalents, e.g. NADH and ATP (formaldehyde and formate dehydrogenases), ADP (dihydroxyacetone kinase) and AMP (fructose-1,6-bisphosphatase) [32]. In methylotrophic yeasts these metabolic pathways operate in accordance with the balance of consumed and produced energy equivalents, thus providing energetic regulation of formaldehyde oxidation and assimilation. Overall, the results seem to reflect the fact that the glucose-only cultivation is NADH-limited and the co-assimilation of methanol as auxiliary substrate may provide an extra direct source of NADH [33].

\section{Impact of Rol secretion on the central carbon metabolism of $P$. pastoris}

As previously observed [12], Rol overproduction had an impact on the substrate specific consumption rate. In addition, both Rol-expressing strains showed slightly lower but significant biomass yields, as well as higher CER and OUR values, compared to the reference strain. This phenomenon might be related to higher energy demand caused by Rol secretion, resulting in higher maintenance-energy requirements. Since Rol amounts were very small relative to the total cell protein, one is tempted to speculate that such metabolic burden was mainly associated to the secretion stress triggered by Rol [23,34], rather than to an increased demand for building blocks. The latter situation seems to occur when recombinant proteins are produced (intracellularly) at high levels in $P$. pastoris $[17,18]$ and other hosts.

The impact of Rol expression on $P$. pastoris core metabolism could be already inferred from the calculated estimated flux ratios (Table 5), reflecting an limited but significant effect of Rol secretion on methanol assimilation, particularly in the ROL 2-copy strain: The relative contribution of methanol to the phosphoenolpyruvate (Pep) pool was decreased, suggesting that a higher fraction of the assimilated methanol was directly oxidised to $\mathrm{CO}_{2}$ (thereby generating $2 \mathrm{~mol}$ of $\mathrm{NADH}$ per mol of methanol) in the Rol-producing strains.

Metabolic flux analysis allowed identification of limited but statistically significant changes in the fluxes through central carbon metabolism (Figure 2 and Additional file 3). Since glucose uptake rates were higher in the Rol-producing strains, glycolytic fluxes were concomitantly increased compared to the reference strain. In addition, the flux of pentose phosphates to the methanol assimilation pathway was significantly decreased in Rol-producing strains, consistent 


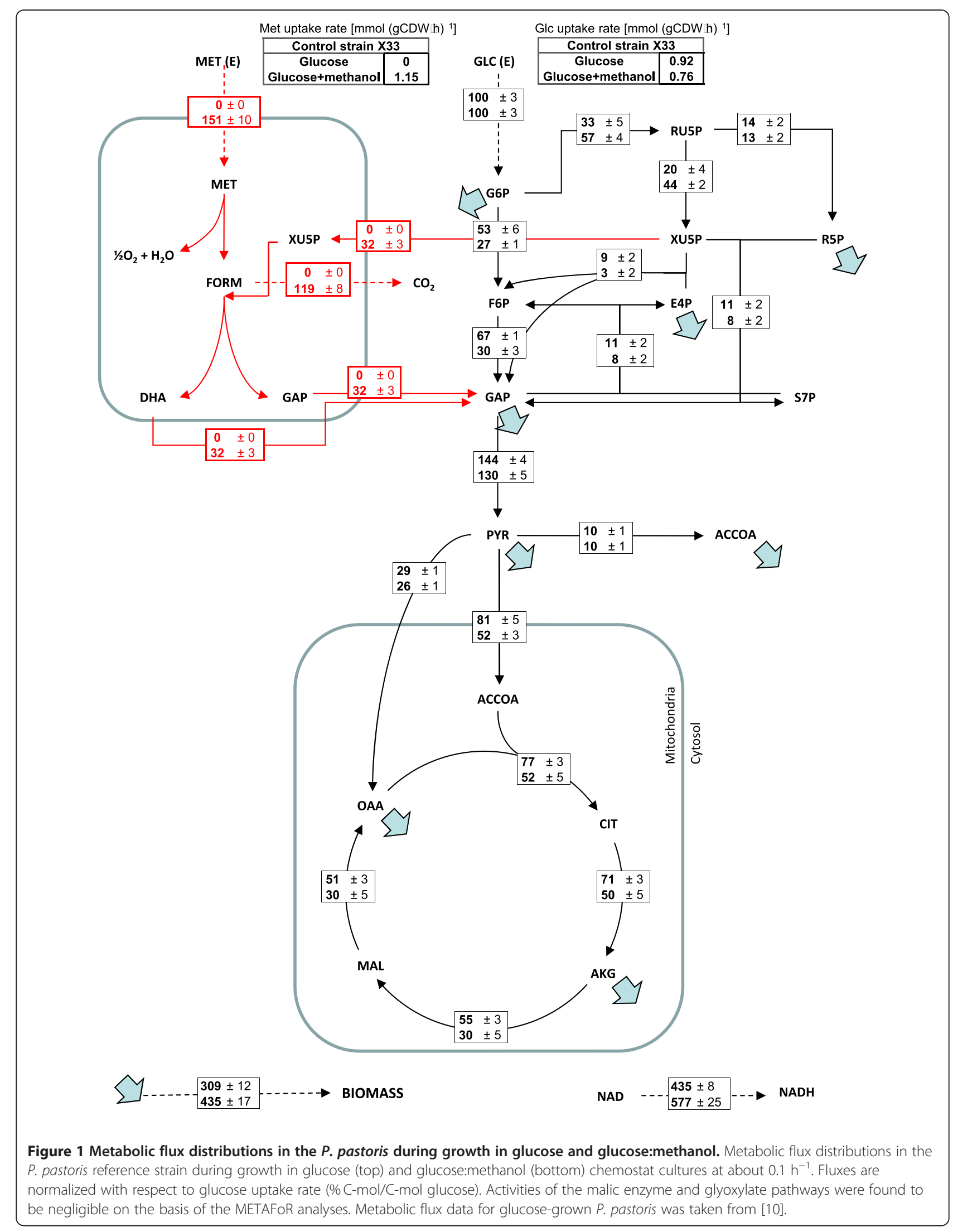


Table 5 Metabolic flux ratio (METAFoR) analysis results

\begin{tabular}{|c|c|c|c|c|}
\hline$\%$ Fraction of total pool & $\mathrm{X}-33$ control & ROL 1- copy & ROL 2-copy & X-33 control* \\
\hline & Glucose:Methanol & Glucose:Methanol & Glucose:Methanol & Glucose \\
\hline Pep from methanol & $45 \pm 5$ & $34 \pm 9$ & $24 \pm 9$ & n.a. \\
\hline Pep from PPP (upper bound) & $14 \pm 4$ & $21 \pm 8$ & $24 \pm 11$ & $39 \pm 9$ \\
\hline R5P from T3P and S7P (transketolase) & $77 \pm 7$ & $70 \pm 1$ & $83 \pm 2$ & $66 \pm 2$ \\
\hline R5P from E4P (transaldolase) & $56 \pm 1$ & $57 \pm 9$ & $56 \pm 4$ & $40 \pm 2$ \\
\hline Ser originating from Gly and C1-unit & $53 \pm 3$ & $55 \pm 2$ & $58 \pm 1$ & $62 \pm 4$ \\
\hline Gly originating from $\mathrm{CO}_{2}$ and $\mathrm{C1}$-unit & $7 \pm 1$ & $12 \pm 1$ & $8 \pm 2$ & $6 \pm 4$ \\
\hline Pep originating from $\mathrm{Oaa}_{\mathrm{cyt}}(\mathrm{PepCK})$ & n.a. & n.a. & n.a. & $2 \pm 5$ \\
\hline $\mathrm{Oaa}_{\text {mit }}$ originating from Pep & $49 \pm 3$ & $42 \pm 12$ & $36 \pm 2$ & n.a. \\
\hline
\end{tabular}

*Data taken from [26].

METAFoR analysis results showing the origins of metabolic intermediates during growth of $P$. pastoris on glucose:methanol compared with those growing on glucose as the sole carbon source, n.a. (not available). Flux ratios used for MFA are highlighted in bold.

with lower fluxes of methanol being assimilated to glyceraldehyde 3-phosphate (GAP), particularly in the ROL 2-copy strain (Figure 3). Notably, although the biomass yield of the Rol-producing strains was somewhat lower compared to the reference strain (also reflected in lower flux to biomass synthesis, Figure 2), the flux through the oxidative branch of the PPP appeared to be similar in all strains. Since one would expect a correlation between the biomass yield and the activity of PPP [35], such effect could be the result of an increased demand of reduction equivalents (NADPH) to regenerate reduced glutathione (GSH) in the endoplasmatic reticulum (ER), the electron donor in the protein folding oxidative process [36,37]. Interestingly, direct methanol dissimilation to $\mathrm{CO}_{2}$ also involves an oxidative step using GSH as electron donor.

Further evidence for a metabolic burden derived from Rol expression was indicated by a significantly increased relative flux through the TCA cycle (normalized to the glucose uptake rate) in the Rol-producing strains. In addition, a tendency to increase the flux through the methanol dissimilatory pathway to $\mathrm{CO}_{2}$ was observed in the Rol-producing strains compared to the reference strain, also reflected in a slight increase in the split ratio between this pathway and the assimilatory pathway to Pep; however, such tendency was not statistically significant. Coherent with these two observations, the respiration rate increased (see CER, OUR and respiratory quotient (RQ) values in Table 1), reflecting a significant increase in $\mathrm{NADH}$ regeneration reactions and, probably, in ATP generation (Figure 2). This would suggest that the metabolic burden caused by Rol secretion is at least partially compensated by increased energy production. That is, the Rol-producing strains appear to have higher maintenance requirements compared to the control strain. Since Rol production levels are moderate, the correlation observed between the specific Rol secretion rates and NADH regeneration rates provide indirect evidence on the metabolic burden associated with protein folding and conformational stress. Interestingly, Heyland and co-workers [17] observed a similar effect (increased TCA cycle flux of $1.1 \mathrm{mmol} \mathrm{g} \mathrm{CDW} \mathrm{h}^{-1}$ in the producing strain compared to $0.7 \mathrm{mmol} \mathrm{g} \mathrm{CDW} \mathrm{h}^{-1}$ in the reference strain) in $P$. pastoris cells producing an intracellular recombinant protein growing on glucose in a fed-batch culture at a controlled growth rate of $0.12 \mathrm{~h}^{-1}$. However, in a recent study by the same group [18], where a series of $P$. pastoris strains expressing different levels of a model recombinant protein exponentially growing in shake cultures (that is, at maximum specific growth rate) were compared, revealed that although there was a relative increase in the relative TCA cycle activity in the producing strains compared to the reference strain, the absolute TCA cycle activity remained constant around $2.1 \pm 0.1 \mathrm{mmol} \mathrm{g} \mathrm{CDW} \mathrm{h}^{-1}$ in all strains, suggesting an upper limit of TCA cycle activity and, thereby postulating that cells do not have the capacity to catabolize a sufficient amount of carbon through the TCA cycle to fully compensate the higher energy demand derived from recombinant protein overproduction. In the present case, the value of the TCA cycle activity was $0.39 \pm 0.03 \mathrm{mmol} \mathrm{gCDW} \mathrm{h}^{-1}, 0.55 \pm 0.03 \mathrm{mmol} \mathrm{gCDW} \mathrm{h}^{-1}$, and $0.57 \pm 0.04 \mathrm{mmol}_{\mathrm{gCDW}} \mathrm{h}^{-1}$ for the control strain, single and 2-copy Rol-producing strains, respectively, clearly below the reported hypothetical activity upper TCA cycle limit for $P$. pastoris growing aerobically on glucose [18]. Furthermore, since there is a significant increase in the absolute flux through the TCA cycle in Rol-producing strains, it seems plausible that there is no energetic limitation at this level in cells growing on glucose:methanol mixtures. In fact, co-assimilation of methanol as auxiliary substrate might be a mechanism by which the increased energy demand of the producing strains is compensated.

\section{Methods}

\section{Strains and media}

A series of recombinant $P$. pastoris X-33 (Invitrogen) derived strains were used in this study. Namely, a control strain harbouring pGAPA $\alpha$ (Invitrogen) as mock plasmid 


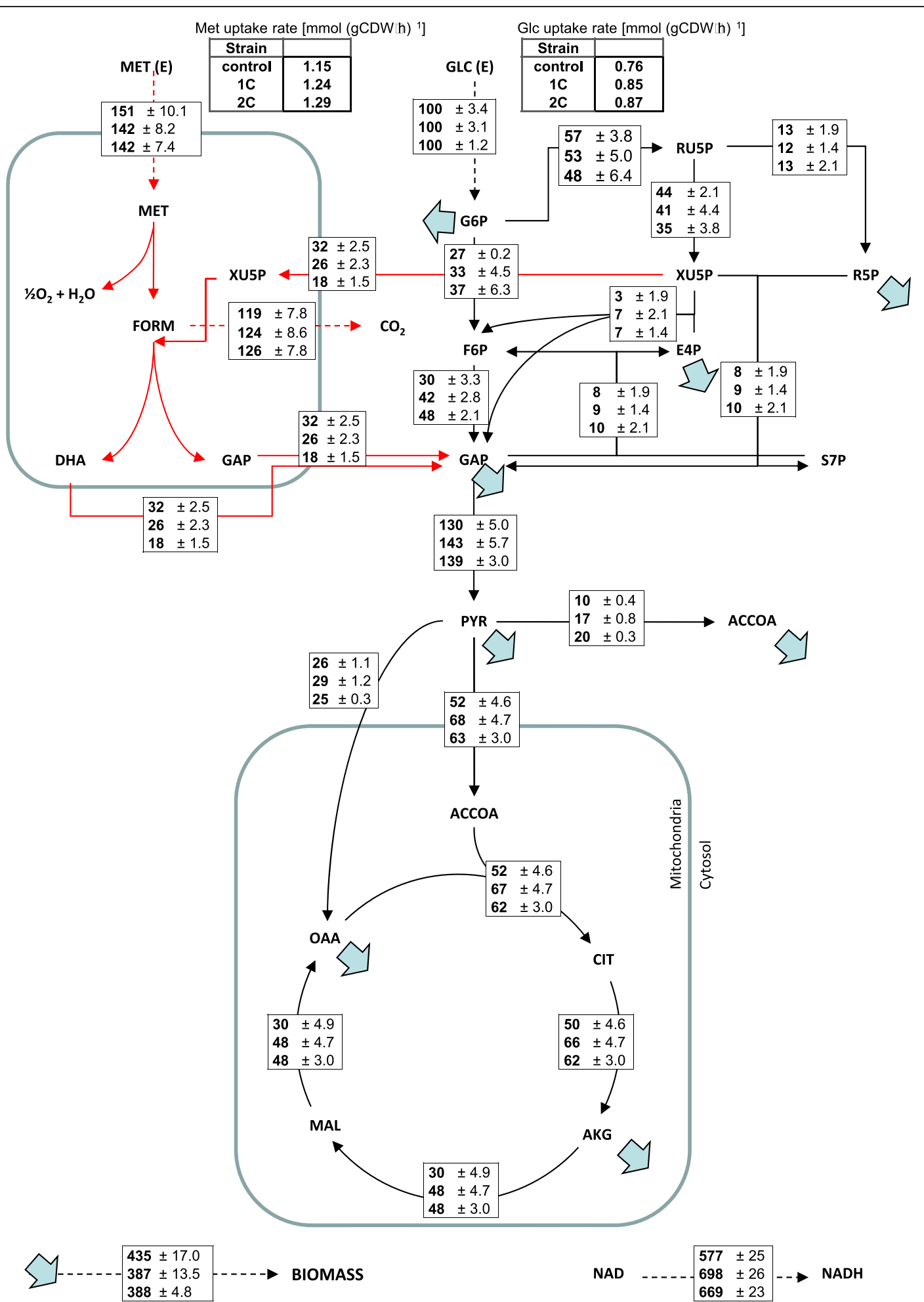

Figure 2 Metabolic flux distributions in the $P$. pastoris reference and recombinant strains during growth on glucose:methanol.

Metabolic flux distributions in the P. pastoris reference strain (top), the recombinant strain with 1 copy of the $R O L$ gene (middle) and the recombinant strain harbouring 2 copies of the $R O L$ gene (bottom) during growth on glucose:methanol chemostat cultures at about $0.09 \mathrm{~h}^{-1}$ Fluxes are normalized with respect glucose uptake flux (\% C-mol/C-mol glucose). Activities of the malic enzyme and glyoxylate pathways were found to be negligible on the basis of the METAFOR analyses. 


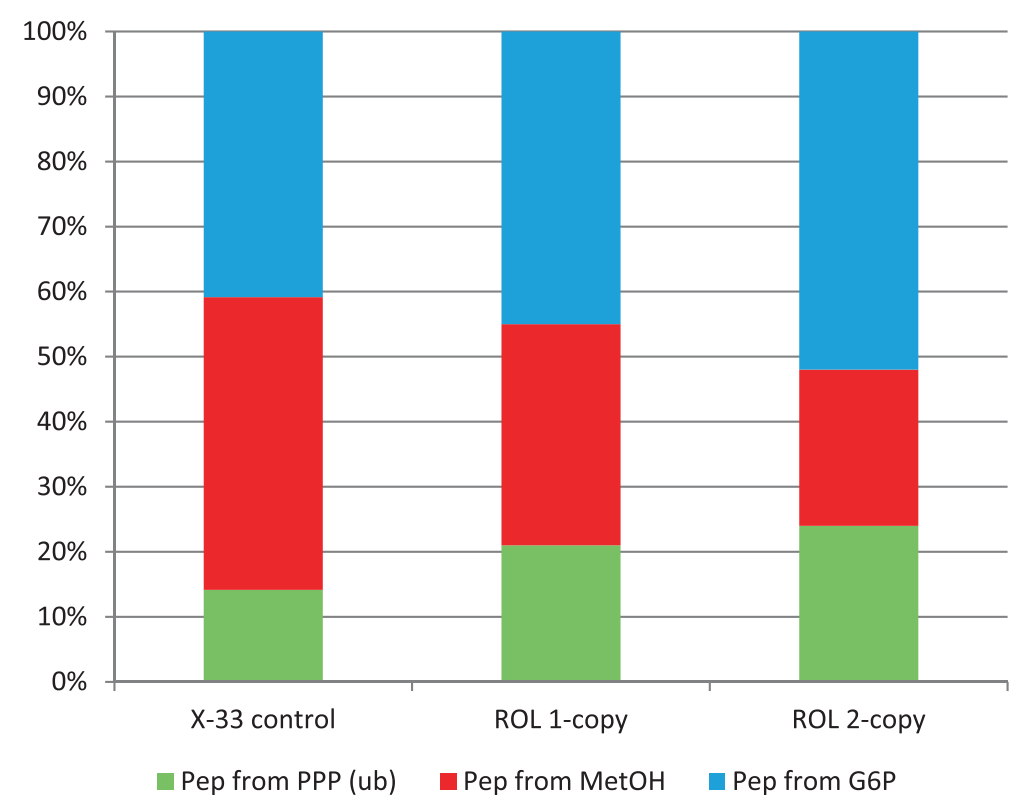

Figure 3 Fractional distributions of carbon fluxes to phosphoenolpyruvate synthesis derived from ${ }^{13} \mathrm{C}$-MFA in P. pastoris. Fractional distributions of carbon fluxes to phosphoenolpyruvate synthesis derived from ${ }^{13} \mathrm{C}-\mathrm{MFA}$ in P. pastoris Rol-producing (ROL 1-Copy and ROL 2-copy) and control (X-33 control) strains growing in glucose-limited chemostats at $D=0.09 \mathrm{~h}^{-1}$.

[26], and two different Rol producing strains: i) the X-33/ pPICZA $\alpha$-ROL strain, previously obtained by [24], regarded as a strain containing a single copy of the $R O L$ expression vector integrated at the host's $A O X 1$ genomic locus and, ii) a strain newly generated in this study following a second transformation of strain X-33 with pPICZA $\alpha$-ROL using a electroporation procedure described by [38]. Prior to transformation, plasmid DNA was linearized to promote integration at the AOX1 locus. Transformants were selected on YPD agar plates containing $100 \mathrm{mg} \mathrm{L}^{-1}$ zeocin (Invivogen) and were subsequently replica-plated onto selection YPD agar plates containing $1000 \mathrm{mg} \mathrm{L}^{-1}$ zeocin, as a strategy to select transformants containing multiple copies of the Rol expression vector integrated in their genome $[12,38,39]$. To select a multi-copy strain with higher expression levels, 10 independent transformants from agar plates containing $1000 \mathrm{mg} \mathrm{L}^{-1}$ zeocin were tested for extracellular lipolytic activity in $500 \mathrm{~mL}$ Erlenmeyers following standard procedures described in the Pichia Expression Kit Manual (Invitrogen). The best clone, was further selected for chemostat studies. Both single and multicopy Rol-producing strains were further characterised in terms of $R O L$ gene dosage by quantitative real-time PCR.

\section{qRT-PCR assay}

Quantitative real-time PCR was carried out in $20 \mu \mathrm{L}$ volume reactions using semi-skirted iQ 96-well PCR plates and SsoFast ${ }^{\mathrm{TM}}$ EvaGreen ${ }^{\circledR}$ Supermix (both from Bio-
Rad). Samples were measured in triplicate and standards were measured in duplicate on the iCycler Thermal Cycler (Bio-Rad). A non template control was run in every experiment for each of the primer pairs to avoid detection of unspecific priming. The reactions were incubated at $95^{\circ} \mathrm{C}$ for $5 \mathrm{~min}$ to activate the Taq polymerase, and then subjected to a three-step cycling protocol including melting $\left(94^{\circ} \mathrm{C}, 15 \mathrm{~s}\right)$, annealing $\left(58^{\circ} \mathrm{C}, 15 \mathrm{~s}\right)$ and extension $\left(72^{\circ} \mathrm{C}, 30 \mathrm{~s}\right)$ for a total of 40 cycles. Each extension was followed by data collection at $72^{\circ} \mathrm{C}$ and a short incubation step at $78^{\circ} \mathrm{C}(1 \mathrm{~s})$ for a second plate reading closer to the melting point. Following a final extension of $5 \mathrm{~min}$ at $72^{\circ} \mathrm{C}$, we generated a melting-curve profile collecting data along 70 cycles with variable temperature starting at $60^{\circ} \mathrm{C}$, with $0.5^{\circ} \mathrm{C}$ increments/ cycle (1-s intervals). The primers used for the amplification reaction were $5^{\prime}$ CCCTGTCGTCCAAGAACAAC 3' and 5' GAGGACCACCAACAGTGAAG 3' (forward and reverse primers, respectively) for the $R O L$ gene; for the reference amplification reaction of the $\beta$-actin gene (ACT1), primers were the same as described previously in [15]. The relative gene expression level was calculated for each sample in triplicate measurements giving a maximum standard deviation around $10 \%$. Since the amplification efficiencies of the target and reference genes were not the same in our experiments, we used the Pfaffl method [40] for the relative quantification of our qRT-PCR results. 


\section{Chemostat cultivations}

Two duplicate aerobic, carbon-limited continuous cultures for each of the three strains were carried out in a $3 \mathrm{~L}$ vessel bioreactor (Applikon Biotechnology) that was controlled at $25^{\circ} \mathrm{C}$. The working volume was kept at $1 \mathrm{~L}$ by means of an overflow system. The $\mathrm{pH}$ was controlled at 5.0 with $1 \mathrm{M}$ $\mathrm{NH}_{3}$. An aeration rate of $1 \mathrm{vvm}$, controlled by the bioreactor's mass flow meters, and a stirring rate of $800 \mathrm{rpm}$ allowed maintaining dissolved oxygen levels at a minimum of $15 \%$ of air saturation. An overpressure of 0.2 bar was applied to the system to facilitate sampling of broth. The chemostat cultures were set at a $D$ of $0.09 \mathrm{~h}^{-1}$ by feeding a defined growth medium [41] containing $50 \mathrm{~g} \mathrm{~L}^{-1}$ of glucose/methanol mixture (80\% glucose / $20 \%$ methanol, w/w) as a carbon source. The bioreactor off-gas was cooled in a condenser $\left(4^{\circ} \mathrm{C}\right)$, dried by means of two silica gel columns and subsequently analyzed with $\mathrm{BCP}-\mathrm{CO}_{2}$ and $\mathrm{BCP}-\mathrm{O}_{2}$ sensors (Blue-Sens). Sensors were calibrated using a series of 3 calibration gases containing $\mathrm{CO}_{2} / \mathrm{O}_{2} / \mathrm{N}_{2}$ mixtures in the following percentages, respectively: $1 / 20.9 / 78.042 ; 3 / 5 /$ 91.97; 7/ 0/93. Steady state samples were taken after the cultures had been in constant conditions for a minimum of five residence times. Steady states were assessed over 4 to 6.5 residence times for constant biomass production CER, OUR, and detectable extracellular metabolites.

\section{Analytical procedures}

Biomass analyses. The cell concentration was monitored by measuring the optical density of cultures at $600 \mathrm{~nm}$ $\left(\mathrm{OD}_{600}\right)$. For cell dry weight $(\mathrm{CDW})$ measurement, $5 \mathrm{~mL}$ of culture broth was filtered using pre-weighed dried glass fiber filters (Millipore). Cells were washed twice using the same volume of distilled water and dried overnight at $100^{\circ}$ C. Triplicate samples $(5 \mathrm{~mL})$ were taken for all optical density and cell dry weight measurements. Biomass samples for the determination of the elemental composition, as well as amino acid, total protein and carbohydrate contents were prepared and analyzed as described by [26]. The measured amino acid content of the biomass allowed on the one hand, estimating the total protein content of the biomass and, on the other hand, calculating a specific protein composition to be used in a synthesis equation for the metabolic flux calculations. The experimentally measured elemental components ( $\mathrm{C}, \mathrm{H}, \mathrm{N}, \mathrm{S}$ and ash content). Oxygen content was calculated by difference as the remaining component. Major macromolecular biomass components (proteins and carbohydrates) were reconciled as previously described [27]. DNA, RNA and lipid content considered in this data consistency analysis were taken from previous measurements [26]. The resulting balanced biomass macromolecular composition was subsequently used for ${ }^{13} \mathrm{C}$-constrained metabolic flux analysis. In all chemostat cultivations, the $\mathrm{C}$ recovery data was above $92 \%$ before applying a data consistency and reconciliation step.
The experimental data was verified using standard data consistency and reconciliation procedures [42-44], under the constraint that the elemental conservation relations were satisfied. For all chemostat cultivations performed, the statistical consistency test carried out with a confidence level of 95\% was acceptable, and consequently accepting that there was no proof for gross measurement errors.

Quantification of extracellular metabolites. Triplicate samples $(5 \mathrm{~mL})$ for extracellular metabolite analyses were centrifuged at 6,000 rpm for $3 \mathrm{~min}$ in a micro centrifuge (Minispin, Eppendorf) to remove the cells, and subsequently filtered through $0.45 \mathrm{~mm}$-filters (Millipore type HAWP). Glucose, methanol, and other potential extracellular compounds were analyzed by HPLC (Dionex Ultimate 3000) analysis using an ionic exchange column, (ICSep ICE-COREGEL $87 \mathrm{H} 3$, Transgenomic). The mobile phase was $6 \mathrm{mM}$ sulphuric acid. The injection volume was $20 \mu \mathrm{L}$ and the chromatogram was quantified with the CROMELEON software (Dionex).

Phosphoenolpyruvate carboxykinase (PepCK) assay. The activity of PepCK was assayed following a method previously described by [45], using the soluble fraction of cell crude extracts obtained after mechanical disruption using glass beads, as described by [46]. Briefly, cell extracts were prepared by mechanical disruption of 15-20 mg of lyophilized cells resuspended in $0.5 \mathrm{~mL}$ of extraction buffer (20 mM Hepes, pH 7.1, 1 mM DTT, $100 \mathrm{mM} \mathrm{KCl}$ ), Complete protease inhibitor cocktail (Roche) and $1 \mathrm{~g}$ of glass beads. Cell suspensions were subsequently vortexed for 6 periods of $30 \mathrm{~s}$, with a $30 \mathrm{~s}$ interval in ice between each vortexing cycle. Samples were centrifuged at $3000 \times \mathrm{g}$ for $5 \mathrm{~min}$ at $4^{\circ} \mathrm{C}$ and the supernatant was subsequently transferred into an Eppendorf tube. A final centrifugation step was carried out in Eppendorf tubes at $5000 \times \mathrm{g}$ for $15 \mathrm{~min}$ and $4^{\circ} \mathrm{C}$ to ensure that the final supernatant was totally clear. The resulting supernatant was used as cellfree extract. PepCK activity was determined following the $340 \mathrm{~nm}$ absorbance of the reduced pyridine nucleotide cofactor $\left(E_{340 \mathrm{~nm}}=6.22 \mathrm{mM}^{-1}\right)$. The reaction mixture $(1 \mathrm{~mL})$ contained $100 \mu \mathrm{mol}$ Imidazole- $\mathrm{HCl}$ buffer, $\mathrm{pH}$ 6.6, $50 \mu \mathrm{mol}$ $\mathrm{NaHCO}_{3}, 2 \mu \mathrm{mol} \mathrm{MnCl}_{2}, 2 \mu \mathrm{mol}$ reduced glutathione, $2.5 \mu \mathrm{mol}$ ADP, $0.15 \mu \mathrm{mol} \mathrm{NADH}, 3 \mathrm{U}$ of malate dehydrogenase (Roche), and cell-free extract, 10 50 $\mu \mathrm{L}$. The reaction was started by adding $2.5 \mu \mathrm{mol}$ Pep. Enzyme activity was measured in a spectrophotometer (Varian Cary 300) at $30^{\circ} \mathrm{C}$ and $340 \mathrm{~nm}$ [45]. One unit activity is defined as the amount of enzyme that catalyzes the formation of $1 \mu \mathrm{mol}$ of reduced pyridine nucleotide per min.

Lipase activity assay. The lipolytic activity was performed as previously described in [47].

\section{Biosynthetically directed fractional (BDF) ${ }^{13} \mathrm{C}$-labelling}

$P$. pastoris cells were fed with a minimal medium containing $50 \mathrm{~g} \mathrm{~L}^{-1}$ of a glucose:methanol mixture $(80 \%$ 
glucose / 20\% methanol, w/w) for five bioreactor volume changes until reaching a metabolic steady state, as indicated by a constant cell density in the bioreactor and constant $\mathrm{O}_{2}$ and $\mathrm{CO}_{2}$ concentrations in the exhaust gas. The ${ }^{13} \mathrm{C}$-labelling experiments were performed in two replicate cultures for each strain.

$\mathrm{BDF}{ }^{13} \mathrm{C}$ labelling of cells growing at steady state on a mix of two carbon source has been described elsewhere [6]. Briefly, as two carbon sources (namely, glucose and methanol) were used, the $\mathrm{BDF}{ }^{13} \mathrm{C}$ labelling step involved feeding the reactor with the medium containing about $12 \%(\mathrm{w} / \mathrm{w})$ of uniformly ${ }^{13} \mathrm{C}$-labelled and $88 \%$ unlabelled amounts of each substrate simultaneously fed for 1.5 volume changes. [ $\mathrm{U}_{-}{ }^{13} \mathrm{C}$ ] glucose (isotopic enrichment 99\%) and ${ }^{13} \mathrm{C}$-methanol (isotopic enrichment 99\%) were purchased from Cortecnet (Voisins le Bretonneux, France). The labelled substrates were fed for a period of 1.5 residence times, after which, a volume of about $500 \mathrm{~mL}$ of culture broth was harvested, centrifuged at $4000 \times \mathrm{g}$ for $10 \mathrm{~min}$, resuspended in $20 \mathrm{mM}$ Tris. $\mathrm{HCl}, \mathrm{pH} 7.6$, and centrifuged again. The recovered and washed cell pellets were freeze dried (Benchtop 5 L Vitris Sentry, Virtis Co., Gardiner, NY, USA). Finally, $100 \mathrm{mg}$ of the freeze dried cell pellets were suspended into $10 \mathrm{~mL}$ of $6 \mathrm{M} \mathrm{HCl}$ and the biomass was hydrolysed in sealed glass tubes at $110^{\circ} \mathrm{C}$ for $22 \mathrm{~h}$. The suspensions were dried overnight in an oven at $90^{\circ} \mathrm{C}$, dissolved in $\mathrm{H}_{2} \mathrm{O}$ and filtered through $0.2 \mu \mathrm{m}$ filters (Millipore). The filtrates were vacuum-dried and dissolved in $\mathrm{D}_{2} \mathrm{O}$ for NMR experiments. The final $\mathrm{pH}$ of the samples was below 1 due to residual $\mathrm{HCl}$.

\section{NMR spectroscopy}

${ }^{1} \mathrm{H}_{-}{ }^{13} \mathrm{C}-\mathrm{HSQC}$ nuclear magnetic resonance (NMR) spectra of the samples were acquired at $40^{\circ} \mathrm{C}$ on a Varian Inova spectrometer operating at a ${ }^{1} \mathrm{H}$-resonance frequency of $600 \mathrm{MHz}$ essentially as described in [28]. For each sample two spectra focusing on the aliphatic and aromatic regions were acquired as previously reported in [28]. The spectra were processed using the standard Varian spectrometer software VNMR (version 6.1, C).

\section{Metabolic flux ratio (METAFoR) analysis}

The software FCAL (R.W. Glaser; FCAL 2.3.1) [29] was used for the integration of ${ }^{13} \mathrm{C}$-scalar fine structures of proteinogenic amino acid carbon signals in the ${ }^{1} \mathrm{H}_{-}{ }^{13} \mathrm{C}-\mathrm{HSQC}$ NMR spectra and for the calculation of relative abundances of intact carbon fragments originating from a single molecule of glucose. The nomenclature used here for the intact carbon fragments, fragmentomers, has also been described previously [48]. Briefly, $f^{(1)}$ represents the fraction of molecules in which the observed carbon atom and the two neighbouring carbons originate from different carbon source molecules (glucose and methanol), $f^{(2)}$ the fraction of molecules in which the observed carbon atom and one of the two neighbouring carbon atoms originate from the same source molecule of glucose, as methanol is a single carbon compound, and $f^{(3)}$ represents the fraction of molecules in which the observed carbon atom and both carbon neighbours originate from the same glucose molecule. In case that the observed carbon exhibits significantly different ${ }^{13} \mathrm{C}-{ }^{13} \mathrm{C}$ scalar coupling constants for the two neighbour carbons, two different fractions, $f^{(2)}$ and $f^{\left(2^{*}\right)}$ are distinguished. In this case, the fraction of molecules with a conserved bond between the observed carbon atom and the neighbouring carbon with the smaller coupling is represented by $f^{(2)}$. Accordingly, $f^{\left(2^{*}\right)}$ then denotes the fraction of molecules where the carbon bond is conserved between the observed carbon and the neighbouring carbon with the larger coupling. If the observed carbon is located at the end of a carbon chain, only the $f^{(1)}$ and $f^{(2)}$ fragmentomers can be observed. The fragmentomer information obtained from the proteinogenic amino acids can be traced back to their metabolic precursors, which are intermediates of central carbon metabolism. The carbon backbones of those eight precursors are conserved in the amino acid synthesis pathways [30]. The compartmentalized metabolic network considered for the METAFoR analysis of $P$. pastoris growing on glucose/methanol mixtures was described in [6]. Due to the assimilation of two different carbon sources, the flux ratio calculation methodology for eukaryotic cells described in [6] was further extended as follows: The fraction of phosphoenolpyruvate (Pep) originating from phosphoenolpyruvate carboxykinase activity was assumed negligible on the basis that this "gluconeogenic" enzyme is not involved in methanol assimilation [19] and its activity appeared to be negligible in $P$. pastoris cells growing under the experimental conditions chosen in this study. Consequently, Pep was considered to originate from three sources: the Pentose Phosphate Pathway (PPP), glycolysis and, the methanol assimilation pathway (Equation 1).

$$
X 1+X 2+X 3+X 4=P e p
$$

Where $\mathrm{X} 1$ and $\mathrm{X} 2$ are the relative fluxes from glyceraldehyde phosphate (GAP) and dihydroxyacetone phosphate (DHAP) to Pep, respectively, both derived from the methanol assimilation pathway, X3 the relative flux from glycolysis to Pep, and X4 is the relative flux from the PPP to Pep. Glycolysis produces fully intact three carbon fragments into Pep molecules [28], whereas the Pep molecules originating from PPP and the methanol assimilation pathway are partially cleaved. Furthermore, the Pep molecules originating from the methanol assimilation pathway possess partially different labelling patterns than the Pep molecules originating from PPP. The contribution of the PPP pathway results in the interconversion of three pentose phosphate molecules to five molecules of Pep. Among the Pep molecules originating from PPP, three fifths retain the C3-C4-C5 fragment of the pentose phosphates, while two fifths possess 
the $\mathrm{C} 1-\mathrm{C} 2$ fragment of the pentose phosphates and a single newly formed $\mathrm{C}-\mathrm{C}$ bond [28]. The methanol assimilation pathway carries the equal pentose phosphate fragments to Pep as PPP but also reversed C3-C4-C5 pentose phosphate fragments since DHAP can reverse the orientation. The methanol is assimilated by forming a six carbon molecule which is then cleaved into two three-carbon compounds, GAP and DHAP. DHAP was assumed to react fully symmetrically. The Pep molecules originating from the reversed DHAP molecules possess different labelling patterns than the Pep molecules originating from PPP. The fraction of Pep originating from the different metabolic pathways was derived from mass balances of the Pep C2 fragmentomers $f^{(2)}$ and $f^{(2 *)}$, whereby back-tracking the amino acid synthesis pathways of Phe-C $\alpha$ and Tyr-C $\alpha$ to the $\mathrm{C} 2$ of Pep [28]. Taking all the above considerations into account the following mass balances were derived from the metabolic reaction carbon mappings of ARM [49] database for the $f^{(2)}$ and $f^{\left(2^{*}\right)}$ fragmentomers of Phe-C $\alpha$ and Tyr-C $\alpha$ :

$$
\begin{aligned}
f^{(2)} & \{\text { Phe }, \text { Tyr }-C \alpha\}=X 1 \cdot f^{(2)}\{\text { His }-C \delta\} \cdot 0.5+ \\
& +X 2 \cdot f^{(2 *)}\{\text { His }-C \alpha\}+ \\
& +X 4 \cdot\left(\frac{2}{5} \cdot f^{(2)}\{\text { His }-C \delta\}+\frac{3}{5} \cdot f^{(2 *)}\{\text { His }-C \alpha\}\right)
\end{aligned}
$$

$$
\begin{array}{r}
f^{(2 *)}\{\text { Phe }, \text { Tyr }- \text { C } \alpha\}=X 1 \cdot f^{(2)}\{\text { His }-C \delta\} \cdot 0.5+ \\
+X 2 \cdot f^{(2 *)}\{\text { His }- \text { C } \alpha\}+X 4 \cdot \frac{3}{5} \cdot f^{(2)}\{\text { His }-C \alpha\}
\end{array}
$$

Taking into account equations (1), (2) and (3), we have formulated the relative contributions of the different pathways to the synthesis of Pep. The relative flux from the methanol assimilation pathway to Pep (XPep_from_Me$\mathrm{tOH}$ ) is a sum of the equal contributions $\mathrm{X} 1$ and $\mathrm{X} 2$ from glyceraldehyde phosphate (GAP) and dihydroxyacetone phosphate (DHAP), respectively (Equation 4). The relative flux from PPP (X4) is named XPep_from_PPP below (Equation 5). The contribution of Glycolysis to the synthesis of Pep (X3) was solved from Equation 1.

$$
\begin{aligned}
& X_{\text {Pep_from_MethOh }}= \\
& =\frac{f^{(2)}\{\text { Phe }, \text { Tyr }-C \alpha\}-X 4 \cdot\left(\frac{2}{5} \cdot f^{(2)} \cdot\{\text { His }-C \delta\}\right)+\frac{3}{5} \cdot f^{(2 *)}\{\text { His }-C \alpha\}}{f^{(2)}\{\text { His }-C \delta\} 0.5+f^{(2 *)}\{\text { His }-C \delta\}}
\end{aligned}
$$

$$
\begin{aligned}
& X_{\text {Pep_-from_PPP }_{-}=} \\
& =\frac{f^{(2 *)}\{\text { Phe }, T y r-C \alpha\}-X 1 \cdot f^{(2)}\{\text { His }-C \delta\} 0.5-X 2 \cdot f^{(2)}\{\text { His }-C \delta\}}{3 / 5 \cdot f^{(2)}\{\text { His }-C \alpha\}}
\end{aligned}
$$

The fraction of mitochondrial oxaloacetate $\left(\mathrm{Oaa}_{\text {mit }}\right)$ originating from $\mathrm{Pyr}_{\text {cyt }}$ through pyruvate carboxylase denoted by $\mathrm{X}_{\text {Oaamit_from_Pyrcyt, was derived from the }}$ mass balance of intact C2-C3 fragments of Oaa (Equation 4). The Oaa molecules originating from the TCA cycle are fully cleaved in C2-C3. Since the flux from Pep to $\mathrm{Pyr}_{\text {cyt }}$ is known to be unidirectional under the carbonlimited cultivation conditions studied here, the Phe-C $\alpha$ and Tyr-C $\alpha$ fragmentomers having Pep as a precursor were used to represent the labelling status of $\mathrm{Pyr}_{\text {cyt }}$. Oaa is the precursor of Asp and Thr and the carbon backbone of $\mathrm{Oaa}_{\text {mit }}$ in particular is conserved also in the TCA cycle and can be observed in Glu. The Asp, Thr and Glu labelling patterns showed an equal cleavage status as their precursor Oaa. Thus, Asp-C $\alpha$ and Thr-C $\alpha$ fragmentomers were used here to represent $\mathrm{Oaa}_{\text {mit }} \mathrm{C} 2$.

$$
X_{\text {Oaa }_{\text {mit }- \text { from_-Pyr }} \text { cyt }}=\frac{\left(f^{(3)}+f^{(2)}\right) \cdot\{\text { Asp, Thr }-C \alpha\}}{\left(f^{(3)}+f^{(2)}\right) \cdot\{\text { Phe }, \text { Tyr }-C \alpha\}}
$$

As described previously [5,28-30], the calculation of metabolic flux ratios when using fractional ${ }^{13} \mathrm{C}$-labeling of amino acids is based on assuming both a metabolic (see above) and an isotopomeric steady state. As stated above, to establish a cost-effective protocol for a larger number of ${ }^{13} \mathrm{C}$ labelling experiments, we fed a chemostat operating in metabolic steady state for the duration of 1.5 volume changes with the medium containing the ${ }^{13} \mathrm{C}$-labelled substrates before harvesting the biomass. Then, the fraction of unlabeled biomass produced prior to the start of the supply with ${ }^{13} \mathrm{C}$-labelled medium can be calculated following simple wash-out kinetics [5].

\section{${ }^{13} \mathrm{C}$-metabolic flux analysis}

${ }^{13} \mathrm{C}$-constrained metabolic flux analysis $\left({ }^{13} \mathrm{C}\right.$-MFA) was performed using a stoichiometric model comprising the major pathways of $P$. pastoris central carbon metabolism. To calculate the intracellular net fluxes, the model was constrained with extracellular flux parameters (evolution rates of biomass, methanol and glucose uptake rate, $\mathrm{CO}_{2}$ uptake rate) and 3 intracellular ratios derived from the METAFoR analysis (see Table 5), as described by [50], thereby constituting a determined system. Therefore, redox cofactors were not used as mass balance constraints to solve the ${ }^{13} \mathrm{C}$ MFA system. Cofactor mass balances are potential sources of errors since the correct balancing requires detailed knowledge of the relative activities of different isoenzymes and the enzyme cofactor specificities on a cell wide scale. Error minimization for the flux calculations in the determined network was carried out as described by [15]. The stoichiometric model of central carbon metabolism of $P$. pastoris was formulated following the model utilized by [15], complemented with the methanol assimilation 
pathways (Additional file 4). Glyoxylate cycle and malic enzyme reaction were omitted from the model on the grounds of the inspection of the METAFoR analysis, as previously described [48]. In this model, the consumption of central metabolic pathway's intermediate metabolites for formation of the major biomass macromolecular components (proteins, carbohydrates, lipids and nucleic acids), was calculated as previously described [26] and considering $P$. pastoris biosynthetic pathways $[5,6,51,52]$. The metabolic fluxes were considered as net fluxes so that a net flux in the forward direction was assigned a positive value and a net flux in the reverse direction was assigned a negative value.

\section{Calculation of NADH regeneration rates}

The rate of $\mathrm{NADH}$ regeneration was derived from the determined fluxes. Once a solution of the metabolic system was found, the metabolic fluxes were used to perform a theoretical calculation of the oxygen consumed. For this purpose, all major steps involved in oxygen consumption were taken into account (essentially, methanol and lipid biosynthesis pathways, as well as all relevant electron balances). Furthermore, it was assumed that all NADPH generated was consumed in biosynthetic reactions. Therefore, all the remaining reduction equivalents were assumed to be recycled through the respiratory chain as any other relevant possibility for recycling has already been taken into account. This allowed calculating the theoretical oxygen consumption rates. The theoretical oxygen consumption rates calculated represented $92 \%$ of the experimentally measured ones. Those results indicate that under the tested experimental conditions, the calculated variables are highly consistent with the experimental ones.

\section{Statistical analyses}

Data are given as mean \pm SEM. Where appropriate, values were compared by a t-test, and significant differences were considered if above a 95\% confidence level $(p<0.05)$.

\section{Conclusions}

Overall, the methodology for MFA based on NMR derived ${ }^{13} \mathrm{C}$ constraints has been extended to the methanol metabolism, thereby enabling the metabolic analysis of recombinant $P$. pastoris growing on substrate mixtures containing methanol. This methodology, which has also been validated by ${ }^{13} \mathrm{C}$-MFA based on GC-MS data (unpublished results, manuscript in preparation) allowed for the quantitative analysis of the additional energy requirements derived from cell's adaptation to stress caused by recombinant protein secretion. Importantly, a limited but significant impact on the energy metabolism could be detected even at relatively low secretion levels when comparing the reference strain with the Rol-producing strains, suggesting that protein folding and conformational stress imposes a burden on the central metabolism. Therefore, it points at the core/energy metabolism as an important target for improvement of recombinant protein production processes in yeast, e.g. by engineering new strains with reduced maintenance requirements, more efficient mechanisms of energy generation or by designing new/improved cultivation processes. Nevertheless, metabolic differences between ROL 1-copy and 2copy producing strains were not statistically significant, suggesting that larger differences in expression/secretion levels are needed in order to have a detectable impact on the central metabolism. Notably, methanol seems to play a key role as auxiliary substrate to compensate for the increased energy demands derived from recombinant protein secretion and favouring metabolic adaptation to the new requirements. This observation could be the underlying explanation why mixed substrate feeding strategies can boost productivities (and reduce metabolic burden) in P. pastoris.

\section{Additional files}

\begin{abstract}
Additional file 1: Biomass macromolecular composition for $P$. pastoris. Macromolecular formula for the reference and two Rolproducing $P$. pastoris strains growing on glucose:methanol mixture (80:20) as a carbon source in chemostat cultures at a $D=0.09 \mathrm{~h}^{-1}$, expressed as C-molecular formula.
\end{abstract}

Additional file 2: Relative abundances of intact carbon fragments in proteinogenic amino acids. Relative abundances of intact C2 and C3 fragments ( $f$-values) in proteinogenic amino acids describing the conservation of carbon chain fragments in P. pastoris Rol-producing and control strains growing in glucose:methanol-limited chemostats at $\mathrm{D}=0.09 \mathrm{~h}^{-1}$

Additional file 3: Metabolic flux distributions in the $P$. pastoris reference and recombinant strains during growth on glucose: methanol. Metabolic flux distributions in the $P$. pastoris reference strain (top), the recombinant strain with 1 copy of the $R O L$ gene (middle) and the recombinant strain harbouring 2 copies of the $R O L$ gene (bottom) during growth on glucose:methanol chemostat cultures at about $0.09 \mathrm{~h}^{-1}$ Activities of the malic enzyme and glyoxylate pathways were found to be negligible on the basis of the METAFoR analyses.

Additional file 4: Stoichiometric model of the central carbon metabolism of $P$. pastoris. Reactions in the stoichiometric model of the central carbon metabolism of $P$. pastoris applied in the ${ }^{13} \mathrm{C}-\mathrm{MFA}$ determination of the metabolic fluxes under different oxygenation conditions; it also includes anabolic reactions from metabolic intermediates to biosynthesis, transport reactions across the mitochondrial membrane and uptake and excretion reactions. Note that $\mathrm{O}_{2}, \mathrm{CO}_{2}$, energy and redox cofactor mass balances were not included in the mass balance constraints in ${ }^{13} \mathrm{C}-\mathrm{MFA}$.

\section{Competing interests}

The authors declare that they have no competing interests

\section{Authors' contributions}

JJ performed bioreactor cultivations and ${ }^{13} \mathrm{C}$-labelling experiments, macroscopic data processing and metabolic flux analysis calculations. PJ and HM, together with JJ, performed the 2D-NMR and METAFoR analyses (including the formulation of new metabolic flux ratios for methanol metabolism), as well as the subsequent interpretation of results. EC constructed the ROL 2-copy strain and performed quantitative real-time PCR for gene dosage quantification. JA designed the ${ }^{13} \mathrm{C}$-constrained MFA approach, and participated in analysis and interpretation of MFA results, as well as in the overall conceptual and 
experimental design of this study. PF participated in the overall conceptual and experimental design, interpretation of results and drafted the manuscript. All authors read and approved the final manuscript.

\section{Acknowledgements}

This study was supported by the Spanish Ministry of Science and Innovation (CICYT projects CTQ2007-60347/PPQ, CTQ2010-15131 and PhD fellowship for J.J.), the Catalan Government (contract grant 2009-SGR-281 and Xarxa de Referència en Biotecnologia). PJ and HM acknowledge the support from the Academy of Finland in Finnish Center of Excellence in White Biotechnology Green Chemistry (grant 118573).

\section{Author details}

'Departament d'Enginyeria Química, Escola d'Enginyeria|, Universitat Autònoma de Barcelona, Bellaterra (Cerdanyola del Vallès), Spain. ${ }^{2} \mathrm{VTT}$ Technical Research Centre of Finland, Espoo, Finland.

Received: 6 January 2012 Accepted: 15 April 2012

Published: 8 May 2012

\section{References}

1. Macauley-Patrick S, Fazenda ML, McNeil B, Harvey LM: Heterologous protein production using the Pichia pastoris expression system. Yeast 2005, 22:249-270.

2. Cos O, Ramón R, Montesinos JL, Valero F: Operational strategies, monitoring and control of heterologous protein production in the methylotrophic yeast Pichia pastoris under different promoters: a review. Microb Cell Fact 2006, 5:17.

3. Bollók M, Resina D, Valero F, Ferrer P: Recent Patents on the Pichia Pastoris Expression System: Expandin the Toolbox for Recombinant Protein Production. Recent Pat Biotechnol 2009, 3:192-201.

4. Porro D, Gasser B, Fossati T, Maurer M, Branduardi P, Sauer M, Mattanovich $D$ : Production of recombinant proteins and metabolites in yeasts: When are these systems better than bacterial production systems? Appl Microbiol Biotechnol 2010, 89:939-948.

5. Solà A, Maaheimo H, Ylönen K, Ferrer P, Szyperski T: Amino acid biosynthesis and metabolic flux profiling of Pichia pastoris. Eur J Biochem 2004, 271:2462-2470.

6. Solà A, Jouhten $P$, Maaheimo H, Sánchez-Ferrando F, Szyperski T, Ferrer P: Metabolic flux profiling of Pichia pastoris grown on glycerol / methanol mixtures in chemostat cultures at low and high dilution rates. Microbiology 2007, 232:433-448.

7. De Schutter K, Lin Y, Tiels P, Van Hecke A, Glinka S, Rouze P, Van de Peer Y, Callewaert N: Genome sequence of the recombinant protein production host Pichia pastoris. Nat Biotechnol 2009, 27:561-566.

8. Graf A, Gasser B, Dragosits M, Sauer M, Leparc GG, Tüchler T, Kreil DP, Mattanovich D: Novel insights into the unfolded protein response using Pichia pastoris specific DNA microarrays. BMC Genomics 2008, 13:1-13.

9. Dragosits M, Stadlmann J, Albiol J, Baumann K, Maurer M, Gasser G, Sauer M Altmann F, Ferrer P, Mattanovich D: The Effect of Temperature on the Proteome of Recombinant Pichia pastoris research articles. J Prot Res 2009, 8:1380-1392.

10. Mattanovich D, Graf AB, Stadlmann J, Dragosits M, Redl A, Maurer M, Kleinheinz M, Sauer M, Altmann F, Gasser G: Genome, secretome and glucose transport highlight unique features of the protein production host Pichia pastoris. Microb Cell Fact 2009, 8:29.

11. Görgens J, van Zyl W, Knoetze J, Hahm-Hägerdal B: The metabolic burden of the PGK1 and ADH2 promoter systems for heterologous xylanase production by Saccharomyces cerevisiae in defined medium. Biotechnol Bioeng 2001, 73:238-245.

12. Cos O, Serrano A, Montesinos JL, Ferrer P, Cregg JM, Valero F: Combined effect of the methanol utilization (Mut) phenotype and gene dosage on recombinant protein production in Pichia pastoris fed-batch cultures. $J$ Biotechnol 2005, 116:321-335.

13. Vigentini I, Brambilla L, Branduardi P, Merico A, Porro D, Compagno C: Heterologous protein production in Zygosaccharomyces bailii: physiological effects and fermentative strategies. FEMS Yeast Res 2005, 5:647-652.

14. Krogh AM, Beck V, Christensen LH, Henriksen CL, Moller F, Olsson L: Adaptation of Saccharomyces cerevisiae expressing a heterologous protein. J Biotechnol 2008, 137:28-33.
15. Baumann K, Maurer M, Dragosits M, Cos O, Ferrer P, Mattanovich D: A multilevel study of recombinant Pichia pastoris in different oxygen conditions. BMC Syst Biol 2010, 4:141

16. Çelik E, Çalik P, Oliver SG: Metabolic flux analysis for recombinant protein production by Pichia pastoris using dual carbon sources: Effects of methanol feeding rate. Biotechnol Bioeng 2010, 105:317-329.

17. Heyland J, Fu J, Blank LM, Schmid A: Quantitative physiology of Pichia pastoris during glucose-limited high-cell density fed-batch cultivation for recombinant protein production. Biotechnol Bioeng 2010, 107:357-368.

18. Heyland J, Fu J, Blank L, Schmid A: Carbon metabolism limits recombinant protein production in Pichia pastoris. Biotechnol Bioeng 2011, 108:1942-1953.

19. Harder M, Veenhuis M: Metabolism of one-carbon compounds. In The Yeasts. Volume 3 (Metabolism and Physiology of Yeast). 2nd edition. Edited by Harrison JS, Rose AH. New York: Academic; 1989:289-316.

20. Jungo C, Schenk J, Pasquier M, Marison IW, von Stockar U: A quantitative analysis of the benefits of mixed feeds of sorbitol and methanol for the production of recombinant avidin with Pichia pastoris. J Biotechnol 2007, 131:57-66.

21. Ramón R, Ferrer P, Valero F: Sorbitol co-feeding reduces metabolic burden caused by the overexpression of a Rhizopus oryzae lipase in Pichia pastoris. J Biotechnol 2007, 130:39-46.

22. Gasser B, Saloheimo M, Rinas U, Dragosits M, Rodríguez-Carmona E, Baumann K, Giuliani M, Parrilli E, Branduardi P, Lang C, Porro D, Ferrer P, Tutino ML, Mattanovich D, Villaverde A: Protein folding and conformational stress in microbial cells producing recombinant proteins: a host comparative overview. Microb Cell Fact 2008, 7:11.

23. Resina D, Bollók M, Khatri NK, Valero F, Neubauer P, Ferrer P: Transcriptional response of $P$. pastoris in fed-batch cultivations to Rhizopus oryzae lipase production reveals UPR induction. Microb Cell Fact 2007, 6:21.

24. Minning S, Serrano A, Ferrer P, Solà C, Schmid RD, Valero F: Optimization of the high-level production of Rhizopus oryzae lipase in Pichia pastoris. $J$ Biotechnol 2001, 86:59-70.

25. Jordà J, Jouhten P, Maaheimo H, Albiol J, Ferrer P: Investigating the potential interactions between energy metabolism and recombinant protein production in Pichia pastoris by ${ }^{13} \mathrm{C}$-based metabolic flux analysis [abstract]. N Biotechnol 2009, 25:\$330.

26. Carnicer M, Baumann K, Töplitz I, Sánchez-Ferrando F, Mattanovich D, Ferrer

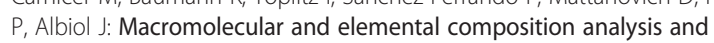
extracellular metabolite balances of Pichia pastoris growing at different oxygen levels. Microb Cell Fact 2009, 8:65.

27. Lange HC, Heijnen JJ: Statistical reconciliation of the elemental and molecular biomass composition of Saccharomyces cerevisiae. Biotechnol Bioeng 2001, 75:334-344.

28. Szyperski T: Biosynthetically directed fractional ${ }^{13} \mathrm{C}$-labeling of proteinogenic amino acids. An efficient analytical tool to investigate intermediary metabolism. Eur J Biochem 1995, 232:433-448.

29. Szyperski T, Glaser RW, Hochuli M, Fiaux J, Sauer U, Bailey JE, Wüthrich K: Bioreaction network topology and metabolic flux ratio analysis by biosynthetic fractional ${ }^{13} \mathrm{C}$ labeling and two-dimensional NMR spectroscopy. Metab Eng 1999, 1:189-197.

30. Maaheimo H, Fiaux J, Çakar ZP, Bailey JE, Sauer S, Szyperski T: Central carbon metabolism of Saccharomyces cerevisiae explored by biosynthetic fractional (13)C labeling of common amino acids. Eur J Biochem 2001, 268:2464-2479.

31. Egli T, Bosshard C, Hamer G: Simultaneous utilization of methanol-glucose mixtures by Hansenula polymorpha in chemostat: Influence of dilution rate and mixture composition on utilization pattern. Biotechnol Bioeng 1986, 28:1735-1741.

32. Trotsenko YA, Bystrykh LV, Ubiyvovk VM: Regulatory aspects of methanol metabolism in yeasts. In Microbial Growth on C1 compounds. Proceedings of the 4th International Symposium on Microbial Growth on One Carbon Compounds. Edited by Crawford RL, Hanson RS. ASM Press; 1984:118-122.

33. Babel W, Müller $\mathrm{RH}$ : Mixed substrate utilitzation in micro-organisms: Biochemical aspects and energetics. J Gen Microbiol 1985, 131:39-45.

34. Resina D, Maurer M, Cos O, Arnau C, Carnicer M, Marx H, Gasser B, Valero F, Mattanovich D, Ferrer P: Engineering of bottlenecks in Rhizopus oryzae lipase production in Pichia pastoris using the nitrogen source-regulated FLD1 promoter. N Biotechnol 2009, 25:396-403.

35. Blank LM, Lehmbeck F, Sauer U: Metabolic-flux and network analysis in fourteen hemiascomycetous yeasts. FEMS Yeast Res 2005, 5:545-558. 
36. Zhu T, Guo M, Zhuang Y, Chu J, Zhang S: Understanding the effect of foreign gene dosage on the physiology of Pichia pastoris by transcriptional analysis of key genes. App/ Microbiol Biotechnol 2011, 89:1127-1135.

37. Delic M, Mattanovich D, Gasser B: Monitoring intracellular redox conditions in the endoplasmic reticulum of living yeasts. FEMS Microbiol Lett 2010, 309:61-66.

38. Cregg JM: DNA-Mediated Transformation. Methods Mol Biol 2007, 389:27-42

39. Serrano A, Lin Cereghino GP, Ferrer P, Cregg JM, Valero F: Overexpression of a Rhizopus oryzae lipase in Pichia pastoris strains containing multiple copies of its gene. In Recombinant protein production with prokaryotic and eukaryotic cells. Acomparative view on host physiology. Edited by Merten O-W. Kluwer Academic; 2001:259-267.

40. Pfaffl MW: A new mathematical model for relative quantification in realtime RT-PCR. Nucleic Acids Res 2001, 29:e45.

41. Baumann K, Maurer M, Dragosits M, Cos O, Ferrer P, Mattanovich D: Hypoxic fed-batch cultivation of Pichia pastoris increases specific and volumetric productivity of recombinant proteins. Biotechnol Bioeng 2008, 100:177-183.

42. Wang NS, Stephanopoulos G: Application of macroscopic balances to the identification of gross measurement errors. Biotechnol Bioeng 1983, 25:2177-2208.

43. Van der Heijden RTJM, Romein B, Heijnen JJ, Hellinga C, Luyben KChAM: Linear constraint relations in biochemical reaction systems: II. Diagnosis and estimation of gross errors. Biotechnol Bioeng 1994, 43:11-20.

44. Verheijen PJT: Data reconciliation and error Detection. In The Metabolic Pathway Engineering Handbook. Edited by Smolke CD. CRC Press; 2010. 8.1-8.13.

45. De Jong-Gubbels P, Vanrolleghem P, Heijnen S, van Dijken JP, Pronk JT: Regulation of carbon metabolism in chemostat cultures of Saccharomyces cerevisiae grown on mixtures of glucose and ethanol. Yeast 1995, 11:407-418.

46. Vandercammen A, François J, Hers HG: Characterization of trehalose-6phosphate synthase and trehalose-6-phosphate phosphatase of Saccharomyces cerevisiae. Eur J Biochem 1989, 182:613-620.

47. Resina D, Serrano A, Valero F, Ferrer P: Expression of a Rhizopus oryzae lipase in Pichia pastoris under control of the nitrogen source-regulated formaldehyde dehydrogenase promoter. J Biotechnol 2004, 109:103-113.

48. Jouhten P, Rintala E, Huuskonen A, Tamminen A, Toivari M, Wiebe M, Ruohonen L, Penttilä M, Maaheimo H: Oxygen dependence of metabolic fluxes and energy generation of Saccharomyces cerevisiae CEN.PK1131A. BMC Syst Biol 2008, 2:60.

49. Arita M: Introduction to the ARM database: Database on chemical transformations in metabolism for tracing pathways. In Metabolomics. The Frontier of Systems Biology. Edited by Tomita M, Nishioka T. Springer-Verlag; 2005:193-210.

50. Fischer E, Zamboni N, Sauer U: High-throughput metabolic flux analysis based on gas chromatography-mass spectrometry derived ${ }^{13} \mathrm{C}$ constraints. Anal Biochem 2004, 325:308-316.

51. Chung BKS, Selvarasu S, Camattari A, Ryu J, Hyeokweon L, Ahn J, Hongweon L, Dong-Yup L: Genome-sacale metabolic reconstruction and in silico analysis of methylotrophic yeast Pichia pastoris for strain improvement. Microb Cell Fact 2010, 9:50.

52. Sohn SB, Graf AB, Yong KIm T, Gasser B, Maurer M, Ferrer P, Mattanovich D, Lee SY: Genome-scale metabolic model of methylotrophic yeast Pichia pastoris and its use for in silico analysis of heterologous protein production. Biotechnol J 2010, 5:705-715.

doi:10.1186/1475-2859-11-57

Cite this article as: Jordà et al:: Metabolic flux profiling of recombinant protein secreting Pichia pastoris growing on glucose:methanol mixtures. Microbial Cell Factories 2012 11:57.

\section{Submit your next manuscript to BioMed Central and take full advantage of:}

- Convenient online submission

- Thorough peer review

- No space constraints or color figure charges

- Immediate publication on acceptance

- Inclusion in PubMed, CAS, Scopus and Google Scholar

- Research which is freely available for redistribution

Submit your manuscript at www.biomedcentral.com/submit
C Biomed Central 